\title{
Influence of sodium starch glycolate, croscarmellose sodium and crospovidone on disintegration and dissolution of stevia-loaded tablets
}

\author{
Abid Mehmood Yousaf ${ }^{1, D}$, Faiza Naheed ${ }^{2, B, C}$, Yasser Shahzad ${ }^{1, E, F}$, Talib Hussain ${ }^{1, E, F}$, Tariq Mahmood ${ }^{2, C, E, F}$ \\ ${ }^{1}$ Department of Pharmacy, COMSATS University Islamabad, Lahore Campus, Pakistan \\ ${ }^{2}$ Faculty of Pharmacy, University of Central Punjab, Lahore, Pakistan \\ A - research concept and design; $\mathrm{B}$ - collection and/or assembly of data; $\mathrm{C}$ - data analysis and interpretation; \\ $D$ - writing the article; $E$ - critical revision of the article; $F$ - final approval of the article
}

Address for correspondence

Abid Mehmood Yousaf

E-mail: abid.ucp@hotmail.com

Funding sources

None declared

Conflict of interest

None declared

\section{Acknowledgements}

All the materials and instrument facilities used in this research were provided by the University of Central Punjab and NovaMed Pharmaceutical Company. No financial support was acquired from any funding source for this research work.

Received on March 22, 2019

Reviewed on June 15, 2019

Accepted on August 5, 2019

Published online on November 18, 2019
Cite as

Yousaf AM, Naheed F, Shahzad Y, Hussain T, Mahmood T. Influence of sodium starch glycolate, croscarmellose sodium and crospovidone on disintegration and dissolution of stevia-loaded tablets. Polim Med. 2019;49(1):19-26. doi:10.17219/pim/111516

DOI

10.17219/pim/111516

Copyright

○) 2019 by Wroclaw Medical University

This is an article distributed under the terms of the

Creative Commons Attribution 3.0 Unported (CC BY 3.0)

(https://creativecommons.org/licenses/by/3.0/)

\section{Abstract}

Background. Sugar substitutes are used by diabetic, obese and calorie-conscious people. As artificial sweeteners are harmful to the body, natural sweeteners are more suitable. Sugar substitutes are available on the market in tablet forms, which are added to hot or cold drinks. Rapid disintegration and dissolution of sugar substitute-loaded tablet is desired. However, the tablets should be hard enough to maintain their integrity during mechanical shocks.

Objectives. The objective of this research was to develop rapidly disintegrating and dissolving stevia-loaded tablets with appropriate wetting, hardness and friability.

Material and methods. Several tablets were prepared using different superdisintegrants using the direct compression method. Flowability tests of the powder blends were performed before compression; these test took into account such physical parameters as bulk density, tapped density, angle of repose, compressibility index, and Hausner's ratio. Evaluation of the compressed cores was accomplished with weight variation, hardness, thickness, friability, disintegration time, wetting time, and dissolution.

Results. The disintegration time and wetting time of the tablets were in the following order: sodium starch glycolate > croscarmellose sodium > crospovidone containing tablets. A powder blend consisting of stevia extract, crospovidone, lactose, and magnesium stearate at the optimized ratio of 15/2.5/32/0.5 (w/w/w/w) showed the best flow, rapid disintegration (38 $\pm 0.894 \mathrm{~s})$, wetting ( $30 \pm 1 \mathrm{~s}$ ), and dissolution ( 95\% in 1 min). Moreover, this formulation showed more rapid wetting (30 \pm 1 s vs $91 \pm 1.9$ s), disintegration ( $38 \pm 0.894$ s vs $143 \pm 1.276$ s) and dissolution ( 95\% vs $60 \%$ in 1 min) than a commercial product.

Conclusions. The tablet consisting of stevia, crospovidone, lactose, and magnesium stearate at the weight ratio of 15/2.5/32/0.5 showed excellent results with regards to dissolution and disintegration; accordingly, this formulation could be a potential sugar substitute for diabetic, obese and/or calorie-conscious individuals.

Key words: superdisintegrants, sugar substitute, hydrophilic polymers, wetting time 


\section{Introduction}

Sweetness is a pleasing sensation produced by the presence of sugars, which are an important substance of daily human life. Sugar beet and sugarcane are the main sources of sugar. However, sugar obtained from these sources is not suitable for diabetic patients, obese and/or calorie-conscious people, as sugar-sweetened food is highly caloric and results in high glycemic index. ${ }^{1,2}$ Consumption of such meals disturbs glucose and insulin levels, alters normal metabolism and hormonal balance, and promotes obesity. ${ }^{1}$ Accordingly, different sugar substitutes are extensively consumed by individuals who are cautious about their health but want to fulfill their craving for sugar. Consumption of diet and drinks which have non-nutritive sweeteners has substantially increased over the past few decades. It is estimated that about $15 \%$ of the US population consumes non-nutritive sweeteners. ${ }^{3}$

A sugar substitute is a food additive which has the taste of sugar but contains few or no calories. ${ }^{4,5}$ It may be obtained from a natural or a synthetic source. Examples of natural sugar substitutes include mannitol, lactitol, xylitol, maltitol, isomalt, sorbitol, etc., while synthetic sugar substitutes include aspartame, calcium cyclamate, thaumatin, saccharin, neotame, acesulfame potassium, sodium cyclamate, sucralose, etc. ${ }^{6}$ On the basis of caloric values, a sugar substitute may be nutritive or non-nutritive. Nutritive sugar substitutes, such as monosaccharides (e.g., sorbitol, xylitol, mannitol, erythritol, etc.), disaccharides (e.g., isomalt, maltitol, isomaltulose, trehalose, etc.) and polysaccharides (e.g., hydrogenated glucose syrup), are caloric sweeteners. ${ }^{7,8}$ Non-nutritive sugar substitutes, such as saccharin, aspartame, neotame, acesulfame-K, cyclamate, dulcin, stevia, and sucralose, are usually noncaloric and produce more intense sweetening sensation than the regular sugar. ${ }^{9}$ Natural sugar substitutes are becoming more popular owing to their harmless nature, while artificial sweeteners possess some documented health hazards. ${ }^{10}$

Stevia, a non-caloric natural sugar substitute, is extracted from leaves of Stevia rebaudiana (Bertoni). Amongst 200 species of genus Stevia, only Stevia rebaudiana possesses property of sweetness. ${ }^{11}$ Stevia contains alkaloids, flavonoids, caffeic acid, chlorogenic acid, oligosaccharides, amino acids, etc. ${ }^{12}$ The chief active sweetening agents in stevia are steviosides, rebaudioside $\mathrm{A}$, rebaudioside $\mathrm{C}$, dulcoside $\mathrm{A}$, and other glycosides of the diterpene steviol. ${ }^{13}$ Steviol (Fig. 1) is the basic structural unit of these glycosides. Stevia is very cheap and easily available; therefore, it has been extensively used for decades to sweeten various foods in Brazil, Korea and Japan. ${ }^{14}$ Stevia enhances insulin sensitivity. ${ }^{8}$ Moreover, it possesses antihypertensive, ${ }^{15,16}$ antihyperglycemic ${ }^{17,18}$ and antiviral ${ }^{19}$ properties. It also has been used in masking the bitter and obnoxious taste of some drugs. ${ }^{20}$

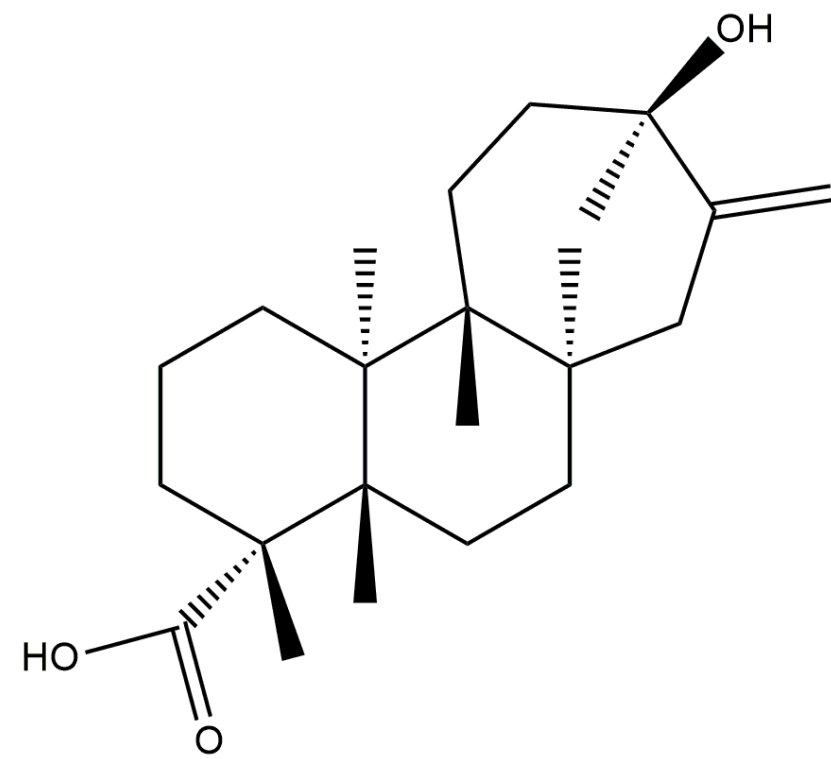

Fig. 1. Structural formula of steviol

Tablets of a sugar substitute undergo in vitro disintegration and dissolution; accordingly, their rapid disintegration and dissolution is desired as soon as they are added to a beverage, coffee or tea. Superdisintegrants, usually hydrophilic polymers, are the excipients which are added to solid dosage forms such as tablets, pellets or granules to help in breaking up the compact mass as it comes in contact with the liquid environment. These are frequently employed for immediate release products, where quick release is the basic requisite. ${ }^{21}$ Superdisintegrants, such as crospovidone, sodium starch glycolate, croscarmellose sodium, etc., can play a significant role in the rapid disintegration and dissolution of such tablets due to their swelling and wetting characteristics. Nevertheless, the tablets should also be hard enough to maintain their integrity during handling, mechanical shocks, blistering, packaging, and transportation. Inadequately friable tablets may crumble during these processes.

Tablets may contain an active ingredient and a number of excipients. In direct compression of tablet formation, all raw constituents are blended well before being subjected to compression under optimized conditions. Adequate flow of powder blend from hopper to die of a tablet machine is necessary for proper formation of tablets. Insufficient flow of powder blend may result in incomplete or very friable tablets.

In the present research, rapidly disintegrating and dissolving tablets were formed using stevia, lactose, magnesium stearate, and different quantities of selected superdisintegrants. The superdisintegrants tested in this study were croscarmellose sodium, crospovidone and sodium starch glycolate. Before direct compression, each powder blend was tested for its flowability by measuring bulk density, tapped density, angle of repose, Hausner's ratio, and compressibility index. ${ }^{22}$ Evaluation of the compressed cores was performed by determining their assay, hardness, friability, 
weight variation, disintegration time, wetting time, and dissolution rate. Fourier transform infrared (FTIR) spectrum of the selected tablet was compared with that of its corresponding powder blend in order to determine the potential chemical interaction among the constituents upon compression. Moreover, wetting time, disintegration time and the dissolution rate of the selected formulation were compared with those of a commercial product.

This research does not involve exploitation of human, animals or other living things as experimental subjects.

\section{Material and methods}

\section{Material}

Stevia extract (Rebaudioside $A$ ) was obtained from Xinghua GL Stevia Co. (Taizhou, China). Sodium starch glycolate was acquired from Hangzhou Zhongbao Co. (Hangzhou, China). Crospovidone was procured from Eurotrade World Commerce, S.L., (Madrid, Spain). Croscarmellose sodium was purchased from Accent Microcell Co. (Ahmedabad, India). Magnesium stearate was bought from Linghu Xinwang Chemical Co. (Huzhou, China). Spray-dried Lactose was purchased from DMV-Fonterra GmbH and Co. (Goch, Germany). Nocal tablets, the commercial product, were kindly gifted by NovaMed Pharmaceutical Co. (Lahore, Pakistan).

\section{Preparation of powder blends for compression}

Each powder blend consisted of stevia extract, spraydried lactose, magnesium stearate, and a superdisintegrant (croscarmellose sodium, crospovidone or sodium starch glycolate) for a batch of 500 tablets. Each superdisintegrant was tested at $2 \%, 3 \%$ and $5 \%$ concentrations. The detailed composition of each powder blend is given in Table 1. For each formulation, all the ingredients were weighed individually on a calibrated electronic weighing balance. At first, lactose was passed through European sieve \#600. Subsequently, stevia extract was sifted from the same sieve and both were thoroughly mixed for $5 \mathrm{~min}$. Then, the select- ed superdisintegrant, at $2 \%, 3 \%$ or $5 \%$ concentration, was sieved and added to this binary blend and mixed for $5 \mathrm{~min}$ again. Finally, magnesium stearate was sieved and poured into the ternary blend and mixed for 5 min again to achieve a final powder blend for direct compression.

\section{Pre-compression flowability of powder blends}

Prior to direct compression, each powder blend was tested for its flow property. Flowability was assessed using Hausner's ratio, compressibility index and angle of repose. ${ }^{22}$ Bulk density $\left(D_{B}, g / \mathrm{cm}^{3}\right)$ and tapped density $\left(D_{\mathrm{T}}, \mathrm{g} / \mathrm{cm}^{3}\right)$ for each powder blend were determined using the KYT-4000 instrument (Seishin Co., Tokyo, Japan). The compressibility index and Hausner's ratio were determined using the following formulas: compressibility index $\left(\mathrm{I}_{\mathrm{C}}\right)=\left(\mathrm{D}_{\mathrm{T}}-\mathrm{D}_{\mathrm{B}}\right) / \mathrm{D}_{\mathrm{T}} \times 100$ and Hausner's ratio $\left(H_{R}\right)=D_{T} / D_{B}$, respectively. The angle of repose was measured using an ABD-72 powder peculiarity tester (Tsutsui Scientific Instruments, Tokyo, Japan). Each powder blend was allowed to flow through the funnel to form a stable symmetrical cone. The formula for the angle of repose is $\theta=\tan ^{-1}(2 \mathrm{~h} / \mathrm{d})$, where $\mathrm{h}$ - height of the pile and $\mathrm{d}-$ mean diameter of the periphery of the cone base.

\section{Formation of tablets}

Nine batches, each comprised of 500 tablets, were prepared via the direct compression method using a ZP-17 rotary tablet press (Shanghai, China). The composition of each tablet is listed in Table 1. For each formulation, the powder blend was subjected to direct compression. The circular tablets of about $5 \mathrm{~mm}$ diameter and $2.5 \mathrm{~mm}$ thickness with both sides plain were obtained for further evaluation.

\section{Evaluation of compressed cores}

\section{Assay of tablets}

Twenty tablets were ground thoroughly using a pestle and mortar. The resultant powder, equivalent to $15 \mathrm{mg}$ stevia extract, was poured into a $50 \mathrm{~mL}$ volumetric flask

Table 1. Composition of powder blends or tablets

\begin{tabular}{|c|c|c|c|c|c|c|c|c|c|}
\hline \multirow{2}{*}{ Constituents [mg] } & \multicolumn{9}{|c|}{ Formulations } \\
\hline & $\mathrm{F} 1$ & $\mathrm{~F} 2$ & F3 & $\mathrm{F} 4$ & F5 & F6 & F7 & F8 & F9 \\
\hline Stevia extract & 15 & 15 & 15 & 15 & 15 & 15 & 15 & 15 & 15 \\
\hline Croscarmellose sodium & 1.0 & 1.5 & 2.5 & - & - & - & - & - & - \\
\hline Crospovidone & - & - & - & 1.0 & 1.5 & 2.5 & - & - & - \\
\hline Sodium starch glycolate & - & - & - & - & - & - & 1.0 & 1.5 & 2.5 \\
\hline Lactose (spray dried) & 33.5 & 33.0 & 32.0 & 33.5 & 33.0 & 32.0 & 33.5 & 33.0 & 32.0 \\
\hline Magnesium stearate & 0.5 & 0.5 & 0.5 & 0.5 & 0.5 & 0.5 & 0.5 & 0.5 & 0.5 \\
\hline Total weight per tablet & 50 & 50 & 50 & 50 & 50 & 50 & 50 & 50 & 50 \\
\hline
\end{tabular}


and completely dissolved in $20 \mathrm{~mL}$ diluent with magnetic stirring for $15 \mathrm{~min}$ at room temperature. The diluent consisted of distilled water and acetonitrile $(68 / 32, \mathrm{v} / \mathrm{v})$. Then, the final volume was made up to $50 \mathrm{~mL}$ and filtered $(0.45 \mu \mathrm{m})$. The theoretical concentration of the resultant solution was $300 \mu \mathrm{g} / \mathrm{mL}$. The actual concentration in the filtrate $(20 \mu \mathrm{L})$ was measured using an HPLC system (LC 20-AT; Shimadzu, Kyoto, Japan). The column used in the analysis was Capcell Pak C18 column (Shiseido, $4.6 \mathrm{~mm}$ I.D. $\times 25 \mathrm{~cm}, 5 \mu \mathrm{m})$ at $40^{\circ} \mathrm{C}$. The mobile phase, $0.01 \mathrm{M}$ sodium phosphate buffer and acetonitrile $(68 / 32, \mathrm{v} / \mathrm{v})$, was eluted at a rate of $1 \mathrm{~mL} / \mathrm{min}$. The eluent was analyzed at $210 \mathrm{~nm}$ for measuring stevia titer. The inter-day and intra-day variances in the precision and accuracy of the method were within the acceptable limits $\left(r^{2}=0.9999\right)$. For each formulation, the assay was performed in triplicate. The assay was determined using the following formula: $\mathrm{S}_{\mathrm{C}}=\mathrm{S}_{\mathrm{A}} / \mathrm{S}_{\mathrm{T}} \times 100$, where $\mathrm{S}_{\mathrm{C}}$ is the assay (\%), $\mathrm{S}_{\mathrm{A}}$ is actual concentration $(\mu \mathrm{g} / \mathrm{mL})$, and $S_{\mathrm{T}}$ is the theoretical concentration $(300 \mu \mathrm{g} / \mathrm{mL})$.

\section{Weight variation}

Twenty tablets were taken randomly for each formulation. Each tablet $(50 \mathrm{mg}$ ) was weighed on a calibrated weighing balance (ATV 224 Model, Shimadzu, Japan). The requirements were met if the average weight of the tablets is within $\pm 10 \%$ range, with no more than 2 tablets differing from the average weight by more than $\pm 10 \%$ and with no tablet differing in weight by $\pm 20 \%{ }^{23}$

\section{Hardness test}

Hardness of the tablet is reflected by the minimum force required to break the tablet in a diametric compression. The hardness of 10 randomly selected tablets was determined using a digital PortTAB-01 portable tablet hardness tester (Torontech ${ }^{\mathrm{TM}}$, Markham, Canada). Each tablet was carefully placed between the 2 jaws. Then, the movable jaw was screwed towards the fixed jaw. For each tablet, the minimum force at which the tablet broke was recorded and the average force of all the tablets was calculated.

\section{Thickness}

Ten tablets were selected randomly from each batch. The thickness of each tablet was measured using a Vernier calipers. Then, the average thickness was calculated and recorded for each batch. ${ }^{24}$

\section{Friability test}

The friability test of tablets was carried out using a Pharmatest PTF3DR 3-drum automated friability testing instrument (Pharma Test Apparatebau AG, Hainburg, Germany). For each formulation, 130 randomly taken tablets were dedusted and weighed carefully. These tablets were placed in the friabilator drum. The friabilator drum was rotated at $25 \mathrm{rpm}$ for $4 \mathrm{~min}$. Then, after the screening of fines, tablets were reweighed. Friability (\%) was determined by the following formula: Friability $(\mathrm{f})=\left(\mathrm{W}_{\mathrm{i}}-\mathrm{W}_{\mathrm{f}}\right) / \mathrm{W}_{\mathrm{i}} \times 100$, where $\mathrm{W}_{\mathrm{i}}$ is the initial weight of the tablets before being subjected to the friability test and $\mathrm{W}_{\mathrm{i}}$ is the final weight of the tablets after the test. The weight of the tablets lost during the test should not exceed $1 \% .{ }^{25}$ The test was performed in triplicate for each batch.

\section{Wetting time}

An aqueous solution of eosin (a water-soluble dye) was prepared using distilled water. Ten milliliters of this solution was poured into a petri dish and spread evenly. Three filter papers, cut in accordance with the inner dimensions of the petri dish, were placed over the spread solution in layers. The solution rapidly seeped across the filter papers due to capillary action. For each formulation, 6 tablets were randomly selected for this test. Each tablet was carefully placed on the soaked filter papers and observed visually for the spreading of blue colour across the tablet. The minimum time for the tablet to become completely blue was noted and regarded as the wetting time of the corresponding tablet. ${ }^{24}$ The average time of wetting for each formulation was calculated.

\section{Disintegration test}

Disintegration test was accomplished using a disintegration tester (Torontech). For each formulation, 6 tablets were randomly taken for this test. One tablet was inserted in each tunnel of the basket and a disc was subsequently introduced. The disintegration was performed using $900 \mathrm{~mL}$ of distilled water as a disintegration medium. The basket speed was set at $30 \mathrm{cycles} / \mathrm{min}$. The test was performed 3 times for each batch. The average disintegration time was calculated along with standard deviation (SD).

\section{Dissolution test}

Dissolution test was performed using the USP dissolution apparatus II (Vision ${ }^{\circledR}$ classic $6^{\mathrm{TM}}$; Hanson Research Co., Los Angeles, USA). For each formulation, 6 tablets were randomly selected for testing. Each $50 \mathrm{mg}$ tablet, containing $15 \mathrm{mg}$ of stevia extract, was dropped in a dissolution vessel containing $500 \mathrm{~mL}$ of distilled water. The temperature of the dissolution medium was maintained at 37 $\pm 0.5^{\circ} \mathrm{C}$ by the surrounding water-bath. The paddle rotation was set at $50 \mathrm{rpm}$. From each dissolution vessel, $1 \mathrm{~mL}$ of the dissolution medium was sampled at each pre-set time intervals ( $0.5 \mathrm{~min}, 1.0 \mathrm{~min}, 3.0 \mathrm{~min}$, and $4.5 \mathrm{~min}$ ), centrifuged at $5000 \times \mathrm{g}$ for $5 \mathrm{~min}$ (5417-R; Eppendorf AG, Hamburg, Germany) and filtered $(0.45 \mu \mathrm{m})$ separately. Each filtrate was analyzed using the HPLC method as described above. 


\section{FTIR spectroscopic analysis}

The Alpha FTIR Spectrometer (Bruker Optik GmbH, Ettlingen, Germany) was used for the FTIR spectroscopic analyses of the selected formulation and its corresponding powder blend or physical mixture. On the sample disc, a minute quantity of the formulation or powder blend was placed in the cavity below the scanning lens. The sample was scanned over a range of $400-4000 \mathrm{~cm}^{-1}$. The selected formulation or the corresponding powder blend consisted of stevia extract, crospovidone, spray-dried lactose, and magnesium stearate $(15 / 2.5 / 32 / 0.5, \mathrm{w} / \mathrm{w} / \mathrm{w} / \mathrm{w})$.

\section{Results and Discussion}

Because tablets containing a sugar substitute are added to a drink or food, their immediate disintegration and dissolution are desired. However, endeavours to achieve rapid disintegration may lead to decreased hardness and increased friability of the tablets. The tablets must be hard enough to endure the mechanical shocks connected with handling, manufacturing, packaging, and transportation. Utilization of superdisintegrants for enhancing disintegration and dissolution rates of tablets, without substantially disturbing hardness and friability, is a good idea.

Superdisintegrants such as crospovidone, sodium starch glycolate and croscarmellose sodium are used as excipients in a solid dosage form to help with the quick dispersal of bound particles, thereby accelerating the dissolution rate; accordingly, they are frequently used as excipients in immediate release products. ${ }^{21}$ The aim of our study was to develop a stevia-loaded tablet which, when added to a drink or food, immediately disintegrates and dissolves to make it sweeter as soon as possible. Therefore, crospovidone, sodium starch glycolate and croscarmellose sodium were used as superdisintegrants in the present research.

Direct compression is the most convenient method to manufacture tablets. It has several advantages including cost-effectiveness, stability, quick dissolution, and simplified process validation. ${ }^{26,27}$ Moreover, the active ingredient and excipients need to be properly mixed before direct compression to enhance content uniformity. Thus, in our research, all the constituents were appropriately blended for each formulation before direct compression. The detailed composition of each batch is shown in Table 1.

Sufficient flow of powder from hopper to die of a tablet machine is essential in the manufacturing of tablets. Otherwise, highly friable tablets are formed, which may crumble during handling and mechanical shocks. Thus, in the present study, powder flowability was assessed. For each powder blend, the values of bulk density, tapped density, angle of repose, Hausner's ratio, and compressibility index are shown in Table 2. The angle of repose, Hausner's ratio, and compressibility index of a powdered substance with a flowability from excellent to fair are $25-36^{\circ}, 1.00-1.25$ and $\leq 10-20 \%$, respectively. ${ }^{22}$ All the powder blends exhibited good or excellent flowability, as the values of these parameters were within the prescribed limits. ${ }^{22}$ Thus, the combinations of constituents in the powder blends were perfect for hinderless flow.

Adequate blending of the constituents and flowability of powder blends result in more apposite content uniformity in the tablets. For batch F1, F2, F3, F4, F5, F6, F7, F8, and F9, the average assay $(\mathrm{n}=3)$ was $99.21 \%$, 98.80\%, 99.20\%, 99.79\%, 99.63\%, 99.19\%, 99.06\%, $98.91 \%$, and $99.76 \%$, respectively. This confirmed that the blending of constituents and flow of powder blend from hopper to die during tablet manufacturing was adequate in our study.

In the weight variation test, the acceptable difference is $\pm 10 \%$ if the average weight of tablets is less than $130 \mathrm{mg}$, $\pm 7.5 \%$ if the average weight of tablets is $130-324 \mathrm{mg}$ and $\pm 5 \%$ if the average weight of tablets is greater than $324 \mathrm{mg} .{ }^{25}$ The values of weight variation $(n=20)$ for all the batches are shown in Table 3. For each formulation, the difference in weight of each tablet from the average weight was within $\pm 10 \%$. Thus, all our formulations passed the weight variation test in accordance with the abovementioned criteria. ${ }^{25}$

Table 2. Pre-compression flowability of powder blend

\begin{tabular}{|c|c|c|c|c|c|}
\hline Formulations & $\begin{array}{l}\text { Bulk density } \\
{\left[\mathrm{g} / \mathrm{cm}^{3}\right]^{*}}\end{array}$ & $\begin{array}{l}\text { Tapped density } \\
{\left[\mathrm{g} / \mathrm{cm}^{3}\right]^{*}}\end{array}$ & $\begin{array}{l}\text { Angle of repose } \\
{\left[\left[^{\circ}\right]^{*}\right.}\end{array}$ & Hausner's ratio* & $\begin{array}{c}\text { Compressibility index } \\
{[\%]^{*}}\end{array}$ \\
\hline F1 & $0.526 \pm 0.003$ & $0.625 \pm 0.005$ & $25.523 \pm 0.050$ & $1.180 \pm 0.005$ & $15.840 \pm 0.013$ \\
\hline F2 & $0.551 \pm 0.007$ & $0.588 \pm 0.002$ & $25.566 \pm 0.100$ & $1.068 \pm 0.020$ & $6.290 \pm 0.063$ \\
\hline F3 & $0.550 \pm 0.002$ & $0.580 \pm 0.005$ & $28.053 \pm 0.050$ & $1.056 \pm 0.015$ & $5.171 \pm 0.033$ \\
\hline F4 & $0.550 \pm 0.003$ & $0.625 \pm 0.007$ & $25.066 \pm 0.060$ & $1.130 \pm 0.001$ & $12.082 \pm 0.060$ \\
\hline F5 & $0.526 \pm 0.007$ & $0.555 \pm 0.006$ & $25.733 \pm 0.060$ & $1.050 \pm 0.007$ & $5.229 \pm 0.005$ \\
\hline F6 & $0.520 \pm 0.008$ & $0.580 \pm 0.006$ & $31.290 \pm 0.150$ & $1.124 \pm 0.006$ & $10.346 \pm 0.001$ \\
\hline F7 & $0.555 \pm 0.013$ & $0.600 \pm 0.006$ & $25.446 \pm 0.100$ & $1.080 \pm 0.005$ & $7.533 \pm 0.057$ \\
\hline F8 & $0.526 \pm 0.003$ & $0.580 \pm 0.005$ & $25.516 \pm 0.030$ & $1.100 \pm 0.050$ & $9.324 \pm 0.078$ \\
\hline F9 & $0.571 \pm 0.010$ & $0.660 \pm 0.002$ & $25.076 \pm 0.130$ & $1.150 \pm 0.050$ & $13.487 \pm 0.042$ \\
\hline
\end{tabular}

* Each value denotes the mean $\pm S D(n=6)$. 
Hardness of tablets should be appropriate. Very hard tablets may fail to disintegrate, while inadequate hardness may result in enhanced friability. Moreover, inappropriate thickness of tablets can create problems during packaging. The mean values of hardness $(n=10)$, thickness $(n=10)$ and friability $(n=3)$ are shown in Table 3. In our study, each tablet demonstrated sufficient hardness for it to be used as a rapidly dispersible tablet. In the friability test, the weight of the tablets lost was $<1 \%$; thus, the tablets passed the test. ${ }^{25}$ Furthermore, thickness values should not be outside $\pm 5 \%$ variation. Thickness values of all the tested tablets were within the acceptable limits.

When a tablet comes in contact with an aqueous medium in vitro or in vivo, water seeps into the tablet, making the superdisintegrants swell in volume, which facilitates disintegration. Thus, wetting is a prerequisite for disintegration and dissolution of a tablet. In our study, all the tablets exhibited complete wetting time results within $\sim 1.5 \mathrm{~min}$. The result of average wetting time $(n=6)$ of each formulation is shown in Table 3. At each concentration level (2\%, $3 \%$ or $5 \%$ ), superdisintegrants with respect to their wetting time were in the order as follows: sodium starch glycolare $>$ croscarmellose sodium > crospovidone. Thus, amongst the 3 superdisintegrants, crospovidone furnished quicker wetting of the tablets than sodium starch glycolate and croscarmellose sodium at all concentration levels. In addition, for each disintegrant, wetting time was reduced as the concentration was increased from $2 \%$ to $5 \%$. In particular, crospovidone at a concentration of $5 \%$ resulted in the quickest wetting of the tablets. Furthermore, the average wetting time of formulation F6 was $30 \pm 1 \mathrm{~s}$ vs $91 \pm 1.9 \mathrm{~s}$ as compared to the commercial product.

The disintegration time results were in accordance with the results of wetting time. The result of average disintegration time $(n=6 \times 3=18)$ of each batch is shown in Table 3. All the formulations showed quicker wetting than the commercial product. At each concentration level, superdisintegrants with respect to their disintegration time were in the order as follows: sodium starch glycolate $>$ croscarmellose sodium $>$ crospovidone. Moreover, for each disintegrant, disintegration time was decreased as the concentration was increased from $2 \%$ to $5 \%$. Among the 3 superdisintegrants, crospovidone exhibited quicker disintegration of the tablets than sodium starch glycolate and croscarmellose sodium at all concentration levels. In particular, crospovidone at a concentration of $5 \%$ demonstrated the quickest disintegration of all the tablets. Furthermore, the average disintegration time of formulation F6 was $38 \pm 0.894 \mathrm{~s}$ vs $143 \pm 1.276 \mathrm{~s}$ as compared to the commercial product.

All the superdisintegrants exerted a positive influence on the dissolution rate of stevia in water. At each concentration level, superdisintegrants with respect to their positive influence on the dissolution rate of stevia in water were in the order as follows: crospovidone > croscarmellose sodium $>$ sodium starch glycolate. Moreover, dissolution rate of stevia was improved as the concentration of a superdisintegrant was increased from $2 \%$ to $5 \%$. At $1 \mathrm{~min}$, the average dissolution rate of formulation F3, F6 and $\mathrm{F} 9$ was $72.64 \pm 3.95 \%, 95.26 \pm 3.70 \%$ and $57.53 \pm 2.87 \%$, respectively (Fig. 2). In particular, the dissolution rate of formulation F6 was $95.26 \pm 3.70 \%$ vs $60.54 \pm 4.38 \%$ in $1 \mathrm{~min}$ as compared to the commercial product.

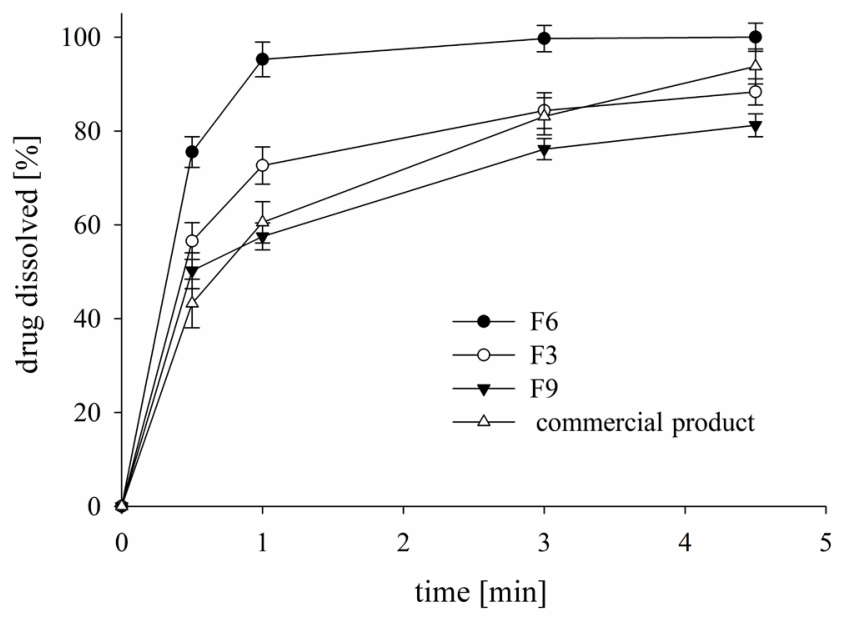

Fig. 2. A comparison of dissolution profiles of selected formulations and the commercial product. Each value of dissolution rate represents the mean $\pm S D(n=6)$

Table 3. Evaluation of compressed cores

\begin{tabular}{|c|c|c|c|c|cc|} 
Formulation & $\begin{array}{c}\text { Weight variation } \\
{[\mathrm{mg}]^{*}}\end{array}$ & $\begin{array}{c}\text { Hardness } \\
{[\mathrm{kg}]^{*}}\end{array}$ & $\begin{array}{c}\text { Thickness } \\
{[\mathrm{mm}]^{*}}\end{array}$ & $\begin{array}{c}\text { Friability } \\
{[\%]^{*}}\end{array}$ & $\begin{array}{c}\text { Disintegration time } \\
{[\mathrm{s}]^{*}}\end{array}$ & $\begin{array}{c}\text { Wetting time } \\
{[\mathrm{s}]^{*}}\end{array}$ \\
\hline F1 & $50.136 \pm 0.457$ & $2.948 \pm 0.256$ & $2.458 \pm 0.041$ & $0.404 \pm 0.045$ & $100 \pm 0.983$ & $90 \pm 1.303$ \\
F2 & $50.976 \pm 0.445$ & $3.019 \pm 0.267$ & $2.481 \pm 0.012$ & $0.493 \pm 0.023$ & $79 \pm 0.752$ & $67 \pm 0.836$ \\
F3 & $51.741 \pm 0.664$ & $2.984 \pm 0.271$ & $2.481 \pm 0.019$ & $0.580 \pm 0.075$ & $59 \pm 1.264$ & $50 \pm 1.341$ \\
F4 & $51.356 \pm 0.571$ & $3.119 \pm 0.464$ & $2.427 \pm 0.020$ & $0.660 \pm 0.052$ & $75 \pm 0.752$ & $65 \pm 0.836$ \\
F5 & $50.786 \pm 0.892$ & $3.087 \pm 0.214$ & $2.428 \pm 0.022$ & $0.576 \pm 0.064$ & $59 \pm 0.727$ & $57 \pm 1.516$ \\
F6 & $50.391 \pm 0.680$ & $3.290 \pm 0.384$ & $2.475 \pm 0.023$ & $0.448 \pm 0.058$ & $38 \pm 0.894$ & $30 \pm 1.000$ \\
F7 & $49.690 \pm 0.808$ & $3.285 \pm 0.352$ & $2.440 \pm 0.023$ & $0.430 \pm 0.112$ & $110 \pm 0.632$ & $95 \pm 0.489$ \\
F8 & $50.338 \pm 0.925$ & $3.315 \pm 0.307$ & $2.420 \pm 0.022$ & $0.536 \pm 0.118$ & $97 \pm 0.983$ & $86 \pm 1.643$ \\
F9 & $51.251 \pm 0.800$ & $3.330 \pm 0.286$ & $2.460 \pm 0.034$ & $0.516 \pm 0.076$ & $80 \pm 1.048$ & $65 \pm 1.732$ \\
\hline
\end{tabular}

* Each value represents the mean \pm SD. 
The FTIR spectra of formulation F6 and its corresponding powder blend are shown in Fig. 3 and Fig. 4, respectively. The FTIR spectral analysis revealed that there was no appearance, disappearance or shift of major peaks after compression. Both the spectra overlapped each other. This suggested the absence of potential chemical interactions among constituents.

Thus, on the basis of the most accelerated wetting, disintegration and dissolution rate, formulation F6 containing stevia, crospovidone, lactose, and magnesium stearate at the weight ratio of $15 / 2.5 / 32 / 0.5$ was selected as the final formulation in our studies. Moreover, it exhibited better wetting, disintegration and dissolution rate as compared to the commercial product. Thus, it can be an effective sugar substitute for diabetics, obese and calorieconscious people.

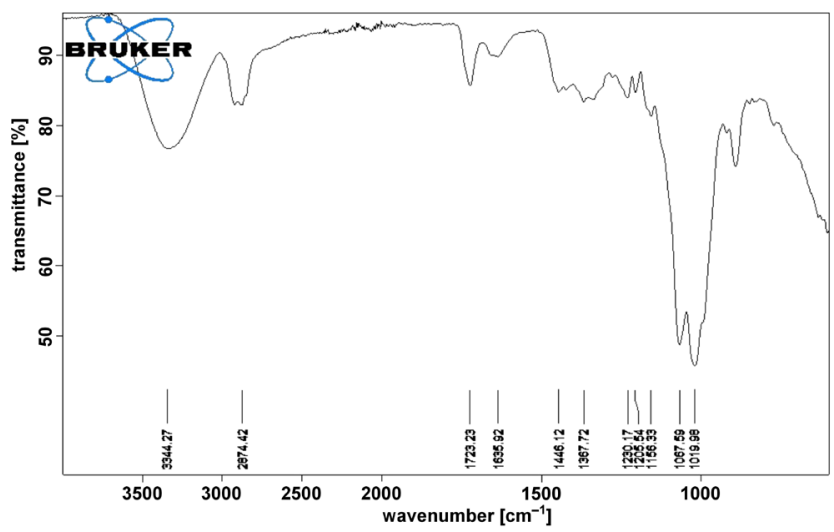

Fig. 3. FTIR spectrum of formulation F6

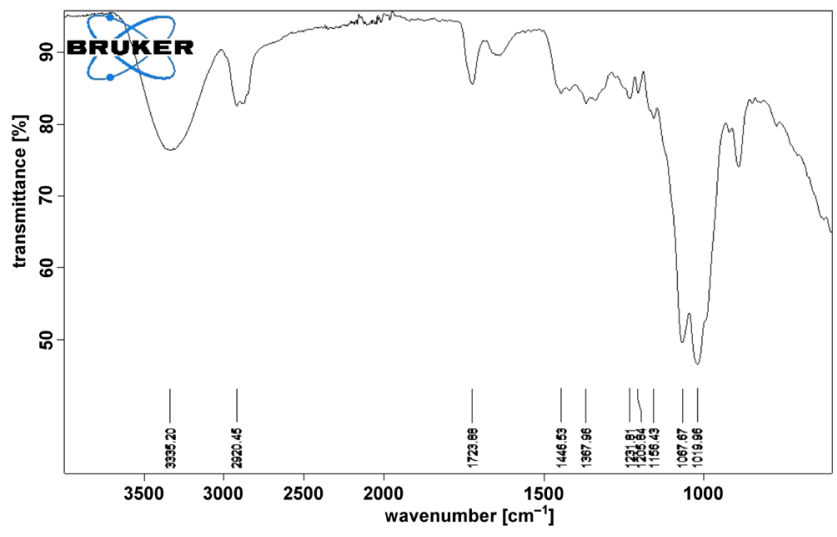

Fig. 4. FTIR spectrum of the powder blend corresponding to formulation F6

\section{Conclusions}

Powder blends of all the formulations exhibited goodexcellent flow. Assay, weight variation, hardness, thickness, and friability of all the tablets were within the acceptable limits. All the superdisintegrants affected the wetting, disintegration and dissolution rate of stevia extract positively. At each concentration level, superdisinte- grants with respect to their positive effect on the wetting, disintegration and dissolution rate of stevia in the aqueous medium were in the order as follows: crospovidone $>$ croscarmellose sodium > sodium starch glycolate. Moreover, wetting, disintegration and dissolution rate of stevia were improved as the concentration of a superdisintegrant was increased from $2 \%$ to $5 \%$. In particular, the formulation F6 containing stevia, crospovidone, lactose and magnesium stearate at the weight ratio of 15/2.5/32/0.5 resulted in the most accelerated wetting, disintegration and dissolution rate of stevia. Also, it exhibited better wetting (average wetting time: $30 \pm 1 \mathrm{~s}$ vs $91 \pm 1.9 \mathrm{~s}$ ), disintegration (average disintegration time: $38 \pm 0.894$ s vs 143 $\pm 1.276 \mathrm{~s}$ ) and dissolution rate (average percent dissolved: $95.26 \pm 3.70 \%$ vs $60.54 \pm 4.38 \%$ in $1 \mathrm{~min}$ ) as compared to the commercial product. Accordingly, this formulation can be an effective sugar substitute for diabetics, obese and calorie-conscious individuals.

\section{ORCID iDs}

Abid Mehmood Yousaf (D) https://orcid.org/0000-0001-7866-9474 Faiza Naheed (1) https://orcid.org/0000-0002-4235-0629 Yasser Shahzad (1) https://orcid.org/0000-0002-0974-2954 Talib Hussain (D) https://orcid.org/0000-0002-0465-9713 Tariq Mahmood (D) https://orcid.org/0000-0001-7097-5442

\section{References}

1. O'Keefe JH, Bell DSH. Postprandial hyperglycemia/hyperlipidemia (postprandial dysmetabolism) is a cardiovascular risk factor. Am J Cardiol. 2007;100(5):899-904.

2. Willett W, Manson J, Liu S. Glycemic index, glycemic load, and risk of type 2 diabetes. Am J Clin Nutr. 2002;76(1):274S-280S.

3. Mattes RD, Popkin BM. Nonnutritive sweetener consumption in humans: Effects on appetite and food intake and their putative mechanisms. Am J Clin Nutr. 2009;89(1):1-14.

4. Raben A, Vasilaras TH, Møller AC, Astrup A. Sucrose compared with artificial sweeteners: Different effects on ad libitum food intake and body weight after $10 \mathrm{wk}$ of supplementation in overweight subjects. Am J Clin Nutr. 2002;76(4):721-729.

5. Bellisle F, Drewnowski A. Intense sweeteners, energy intake and the control of body weight. Eur J Clin Nutr. 2007;61(6):691-700.

6. Renwick AG. The intake of intense sweeteners: An update review. Food Addit Contam. 2006;23(4):327-338.

7. Fitch C, Keim KS. Position of the Academy of Nutrition and Dietetics: Use of nutritive and nonnutritive sweeteners. J Acad Nutr Diet. 2012;112(5):739-758.

8. Chang JC, Wu M, Liu IM, Cheng JT. Increase of insulin sensitivity by stevioside in fructose-rich chow-fed rats. Horm Metab Res. 2005;37(10):610-616.

9. Gupta C, Prakash D, Gupta S, Goyal S. Role of low calorie sweeteners in maintaining dental health. Middle East J Sci Res. 2012;11(3):342-346.

10. Duffy VB, Anderson G. Position of the American Dietetic Association: Use of nutritive and nonnutritive sweeteners. J Am Diet Assoc. 1998;98(5):580-587.

11. Savita S, Sheela K, Sunanda S, Shankar A, Ramakrishna P, Sakey S. Health implications of Stevia rebaudiana. J Hum Ecol. 2004;15(3):191-194.

12. Komissarenko N, Derkach A, Kovalyov I, Bublik N. Diterpene glycosides and phenylpropanoids of Stevia rebaudiana Bertoni. Rast Res. 1994;1(2):53-64.

13. Soejarto D, Compadre C, Medon P, Kamath S, Kinghorn A. Stevia: Steps in developing a new sweeteners, developments in sweeteners. Econ Bot. 1983;37:71.

14. Kinghorn A, Compadre C. Alternative Sweeteners. $3^{\text {rd }}$ ed. Boca Raton, FL: CRC Press; 2001. 
15. Chan P, Tomlinson B, Chen YJ, Liu JC, Hsieh MH, Cheng JT. A double-blind placebo-controlled study of the effectiveness and tolerability of oral stevioside in human hypertension. Br J Clin Pharmacol. 2000;50(3):215-220.

16. Lee CN, Wong KL, Liu JC, Chen YJ, Cheng JT, Chan P. Inhibitory effect of stevioside on calcium influx to produce antihypertension. Planta Med. 2001;67(9):796-799.

17. Jeppesen PB, Gregersen S, Alstrup K, Hermansen K. Stevioside induces antihyperglycaemic, insulinotropic and glucagonostatic effects in vivo: Studies in the diabetic Goto-Kakizaki (GK) rats. Phytomed. 2002;9(1):9-14.

18. Jeppesen PB, Gregersen S, Poulsen C, Hermansen K. Stevioside acts directly on pancreatic $\beta$ cells to secrete insulin: Actions independent of cyclic adenosine monophosphate and adenosine triphosphatesensitivie $\mathrm{K}^{+}$-channel activity. Metabolism. 2000;49(2):208-214.

19. Das S, Das A, Murphy R, Punwani I, Nasution M, Kinghorn A. Evaluation of the cariogenic potential of the intense natural sweeteners stevioside and rebaudioside A. Caries Res. 1992;26(5):363-366.

20. Parsons WT, Parsons WT, Cuthbertson E. Noxious Weeds of Australia. Clayton, Australia: CSIRO Publishing; 2001.

21. Seager $H$. Drug-delivery products and the Zydis fast-dissolving dosage form. J Pharm Pharmacol. 1998;50(4):375-382.

22. Chapter G. <1174> Powder flow. USP33-NF28. 2010. https://www. scribd.com/document/374151661/0801-0804-1174-POWDERFLOW-USP-35 (Accessed on March 22, 2019).

23. Rockville M. United States Pharmacopoeia. Paper presented at: United States Pharmacopoeial Convention Inc., Washington, Washington D.C., 2002.

24. Barathi N. Sweeter alternative. Times Agri J. 2003;14.

25. Revision USPCCo. The United States Pharmacopeia 42; 2019.

26. Shah NH, Ahmed HA. Content uniformity of a low dose pharmaceutical product. Particul Sci Technol. 1997;15(2):151-151.

27. Matinez L, Tchoreloff $P$, Leclerc B, Besnard M, Couarraze G. Active layering and direct compression of sugar spheres: Content homogeneity in low-dosage tablets. Pharm Technol Eur. 2001;38-46. 